\title{
WATER EXTRACTION ON THE HYPERSPECTRAL IMAGES OF GAOFEN-5 SATELLITE USING SPECTRAL INDICES
}

\author{
Y. Liu ${ }^{1, *}$, C. C. Xiao ${ }^{1}$ \\ ${ }^{1}$ Land Satellite Remote Sensing Application Center, Ministry of Natural Resources of P.R.China, 100048 Beijing, China - \\ (liuyao,xiaocc)@lasac.cn
}

KEY WORDS: water extraction, remote sensing, Gaofen-5 satellite, hyperspectral imagery, water spectral indices, histogram bimodal method

\begin{abstract}
:
Water extraction from remote sensing images can be applied in water resources monitoring, as well as an essential preprocessing for water quality parameter retrieval. China's new generation Gaofen-5 satellite carries a hyperspectral imager named AHSI, which is suitable for water quality monitoring. In this paper, to determine the spectral index most suitable for AHSI data's water extraction, we selected a large lake and a reservoir in China as the study areas, and used corresponding AHSI data for water extraction experiment. In the experiment, NDWI, MNDWI and AWEI were all tested on the AHSI reflectance data, and major water bodies were delineated by implementing the histogram bimodal method on the water index images. Based on analyses with water index images and water extraction results, NDWI is shown to be the optimal index for water extraction of AHSI data among these three widely-used indexes, as it can accurately extract water bodies and also eliminate pixels of water plants or shadows between land and water. In addition, MNDWI can be used on AHSI data since it is most robust in terms of providing a bimodal histogram. AWEI is, however, not suggested to be used for water extraction of the AHSI data.
\end{abstract}

\section{INTRODUCTION}

As an important part of water resources, land surface water, including lakes, rivers and reservoirs, changes dynamically in time and space. It is necessary to identify water body ranges regularly for water resource management, ecosystem protection, hydrology process understanding and so on (Feng et al., 2019, Rai et al., 2018, Guo et al., 2017). Since remote sensing has become a useful means to acquire data for monitoring and analyzing the surface water changes, various methods have been developed for delineation of open water. Existing methods could be divided into four categories: (1) thresholding based on spectral characteristics (Jain et al., 2005, Xu, 2006, Feyisa et al., 2014, Zhang et al., 2018), (2) image segmentation based on local features (He et al., 2016, Kaplan, Avdan, 2017), (3) machine learning classification method (Isikdogan et al., 2017, Chen et al., 2018, Wang et al., 2019), (4) mathematical-morphology driven approach (Daya Sagar et al., 1995, Rishikeshan, Ramesh, 2018). Among these methods, the first category is most widely-used, especially the threshold segmentation based on water spectral indices, because it is easy to understand and calculate.

In the past several decades, several water spectral indices have been proposed for remote sensing data. Normalized Difference Water Index (NDWI) was introduced for water delineation of Landsat TM using its green and near infrared (NIR) bands (McFeeters, 1996). Considering that NDWI cannot efficiently suppress the signal from built-up areas, modified NDWI (MNDWI) was then proposed, with a short-wave infrared (SWIR) band to replace the NIR reflectance in NDWI (Xu, 2006). Another water index called automated Water Extraction Index (AWEI) was also developed, with the objective to improve accuracy by automatically suppressing classification noise from shadow and other non-water dark surfaces (Feyisa et al., 2014).
Specifically, two AWEIs are developed: $\mathrm{AWEI}_{n s}$ is for nonshadow conditions, and $\mathrm{AWEI}_{s h}$ is suited for areas with shadow and/or other dark surfaces. Compared with MNDWI and NDWI applied on Landsat imagery, AWEI also uses the Blue band (band 1) and one more SWIR band (band 7).

Water indices mentioned above are mainly used on multi-spectral imagery. Also, hyperspectral images can use this method for water area extraction. Remarkably, China launched the new generation hyperspectral comprehensive observation satellite named Gaofen-5 on May 9, 2018. This satellite carries six payloads, one of which is an Advanced Hyperspectral Imager (AHSI) that contains 330 bands covering the spectral range of $400-2500 \mathrm{~nm}$, with a spectral resolution of $5 \mathrm{~nm}$ and $10 \mathrm{~nm}$ in the visible to near-infrared (VNIR) and short-wave infrared (SWIR) bands, respectively (Liu et al., 2019). Besides, it can collect images with a $60-\mathrm{km}$ swath width at the $30-\mathrm{m}$ spatial resolution. AHSI's high spectral resolution is an important advantage for water quality parameter estimation (Koponen et al., 2002, Brando, Dekker, 2003), As such, water extraction is an essential preprocessing for the retrieval of water quality parameter images.

In this paper, we aim to find an optimal water spectral index to perform AHSI's water extraction. Therefore, AHSI images having water bodies with various background land covers were selected, and water extraction experiments were conducted using common water indices. Section 2 introduces the study areas and experiment data. The water extraction method for AHSI imagery is detailed in Section 3. Section 4 provides the water delineation results using different spectral indices, and making comparison through visual inspection. Finally, conclusions are made in terms of the water extraction for the AHSI data in Section 5.

\footnotetext{
* Corresponding author
} 


\section{STUDY AREAS AND DATA}

Nansi Lake and Guanting Reservoir, which are two inland water bodies in China, are selected as the study areas. Nansi Lake consists of four interconnected lakes, which are Weishan Lake, Shaoyang Lake, Dushan Lake and Nanyang Lake. It is located in the Weishan County of Shandong Province, and it's the largest lake in the North China with an area of 1266 square kilometres. Guanting Reservoir is located at Huailai county of Hebei province, and serves as one of the standby drinking water sources for Beijing. It was constructed in 1954, and it has an area of 130 square kilometres. Two AHSI images collected at these places are selected, and subset images with water areas are used as the experiment data (see Table 1). In the Nansi Lake scene, this lake is surrounded with built-up areas and farmland, and a lot of fish ponds lie along the lake. In the Guanting Reservoir image, the reservoir lies among hills covered with trees, bare soil and farmland.

\begin{tabular}{|c|c|c|}
\hline Study Area & Nansi Lake & Guanting Reservoir \\
\hline Acquisition Date & Apr. 1, 2019 & May 22, 2019 \\
\hline Image Size (pixels) & $1357 * 1357$ & $850^{* 793}$ \\
\hline Longitude & 117.23 & 115.73 \\
\hline Latitude & 34.77 & 40.19 \\
\hline
\end{tabular}

Table 1 Experiment images of AHSI onboard Gaofen-5 Satellite with water bodies.

\section{METHOD}

\subsection{Image Preprocessing}

In this paper, water indices are calculated based on the surface reflectance of AHSI images. Since level-1 AHSI images are in the form of digital numbers $(\mathrm{DN})$, they are required to be calibrated to surface reflectance through atmospheric correction. This process is carried out using the ENVI software in four steps. First, as VNIR and SWIR data of AHSI are separately stored, these two images are merged into one file, and central wavelengths and Full-Width-Half-Maximum (FWHM) of each band are added into the header file. Second, radiometric calibration is conducted on the 330-band DN data to acquire radiance images. Third, radiance images are then transferred to Band-interleaved-by-pixel (BIP) or Band-interleaved-by-line (BIL) format. Last, Fast Line-of-Sight Atmospheric Analysis of Spectral Hypercubes (FLAASH) module in ENVI is chosen to perform atmospheric correction (Cooley et al., 2002). Specifically, parameters in FLAASH are set as follows: 1) BIP/BIL radiance files are input of FLAASH; 2) zenith and azimuth angles are acquired from the AHSI's metadata file, and atmospheric model is selected according to the imaging time; 3 ) the band image close to $940 \mathrm{~nm}$ is selected to detect water absorption feature, and rural/urban aerosol model is used with 2band (K-T) method for the aerosol amount retrieval and the scene average visibility estimation. Surface reflectance images of the study areas retrieved from above process are displayed in Figure 1 and Figure 2.

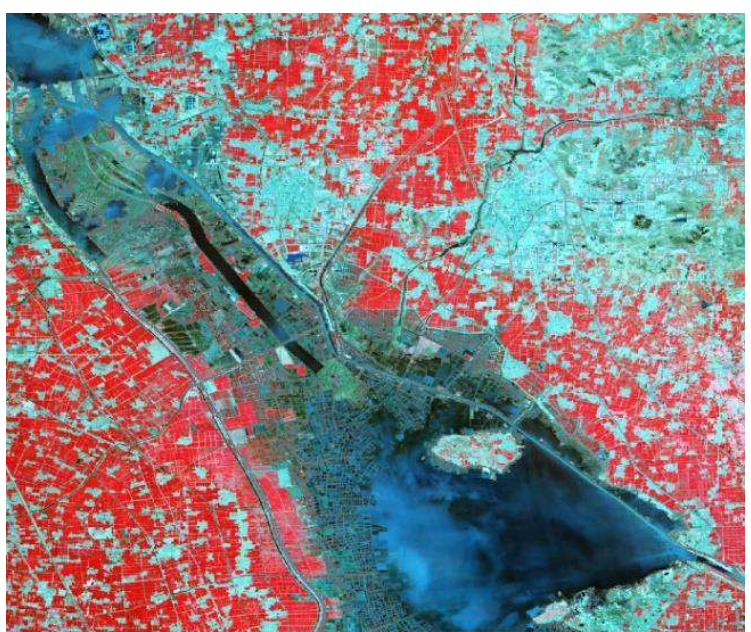

Figure 1. False-color composite of the AHSI surface reflectance image of Nansi Lake

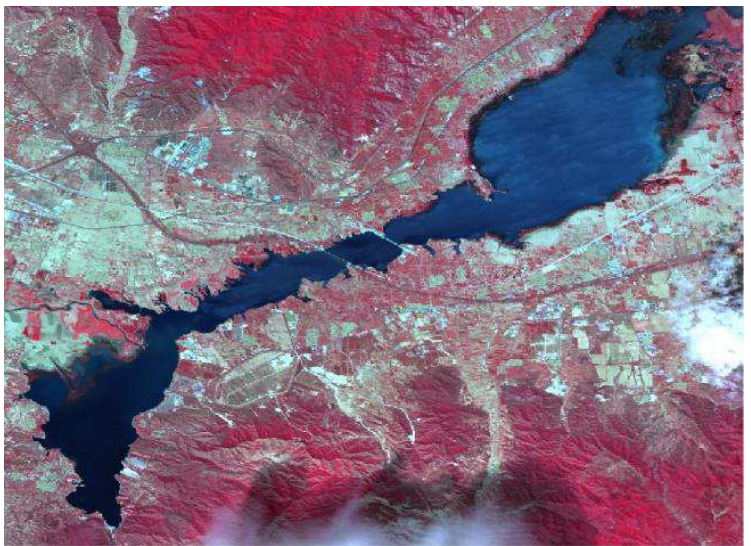

Figure 2. False-color composite of the AHSI surface reflectance image of Guanting Reservoir

\subsection{Water Extraction}

After the retrieval of the surface reflectance images, the water index images can be calculated for the AHSI data. In this paper, three widely-known indexes (i.e., NDWI, MNDWI, and AWEI ${ }_{n s h}$ ) are selected. Please kindly note that only $\mathrm{AWEI}_{n s h}$ is used. Although $\mathrm{AWEI}_{s h}$ is proposed for areas with shadow and/or dark surroundings, its performance on AHSI data is unsatisfying in terms of dark pixels than that of the NDWI and MNDWI according to preliminary experiment results. Also, the histogram of $\mathrm{AWEI}_{s h}$ shows multiple peaks, which is unfavourable for determination of the threshold to extract water area. Three selected water indices can be expressed as follows:

$$
\begin{gathered}
N D W I=\frac{\rho_{G}-\rho_{\text {NIR }}}{\rho_{G}+\rho_{\text {NIR }}} \\
M N D W I=\frac{\rho_{G}-\rho_{\text {SWIR } 1}}{\rho_{G}+\rho_{\text {SWIR } 1}} \\
A W E I_{n s h}=4 *\left(\rho_{G}-\rho_{\text {SWIR } 1}\right)-\left(0.25 * \rho_{\text {NIR }}+2.75 * \rho_{\text {SWIR } 2}\right)
\end{gathered}
$$

where $\rho_{G}$ is reflectance in green band, $\rho_{N I R}$ is NIR band reflectance, $\rho_{\text {SWIR } 1}$ and $\rho_{\text {SWIR } 2}$ are reflectance in different SWIR bands. It should be noted that these three indices are all initially proposed for Landsat TM data, and the spectral range of these bands are 0.52-0.60 $\mu \mathrm{m}$ (green), 0.76-0.90 $\mu \mathrm{m}$ (NIR), 1.55-1.75 $\mu \mathrm{m}$ (SWIR1) and 2.08-2.35 $\mu \mathrm{m}$ (SWIR2). 
As the narrow band data of AHSI has relatively low signal-tonoise ratio, noise becomes a common problem, especially in its SWIR bands. Selecting single bands to calculate the water index is unsuitable for AHSI data. To tackle this problem, water indices are calculated on a broadband scale. Specifically, we use average reflectance in the spectral range of Landsat TM bands to calculate NDWI, MNDWI, and AWEI ${ }_{n s h}$ for the AHSI data. Then, the histogram bimodal method (HBM) is applied for threshold selection of recognizing waters from other land cover types $(\mathrm{Li}$ et al., 2011, Khandelwal et al., 2017). At last, water areas with less than 1000 pixels ( $\sim .9$ square kilometre) are eliminated to retain the main waterbody area.

\section{EXPERIMENTAL RESULTS}

\subsection{Water Index Image Results}

Water index images generated from the AHSI reflectance data are shown in Figure 3-5 for Nansi Lake and Figure 6-8 for Guanting Reservoir. In addition, histograms of the index image are also provided. Comparing Figure 3-5, it can be seen that all three water indices have distinct values for water and non-water areas in AHSI data. Among them, MNDWI shows obvious strip noise in water areas (see Figure 4), this is due to the strip noise existing in the SWIR bands of AHSI data. However, MNDWI also provides the most significate difference between pixels of the water body and other surface types, as well as the most desirable bimodal shape in histogram. On the other hand, NDWI and AWEI have distinct values for not only the water but also other land cover types, resulting in three peaks in their histogram. More than two peaks appear in the histogram is because the nonwater pixels have different water index values, and the number of these pixels are comparable to that of water pixels. Such shape in histogram makes threshold more difficult to determine for HBM, but this issue can be fixed by finding an optimal threshold after testing on abundant AHSI images.

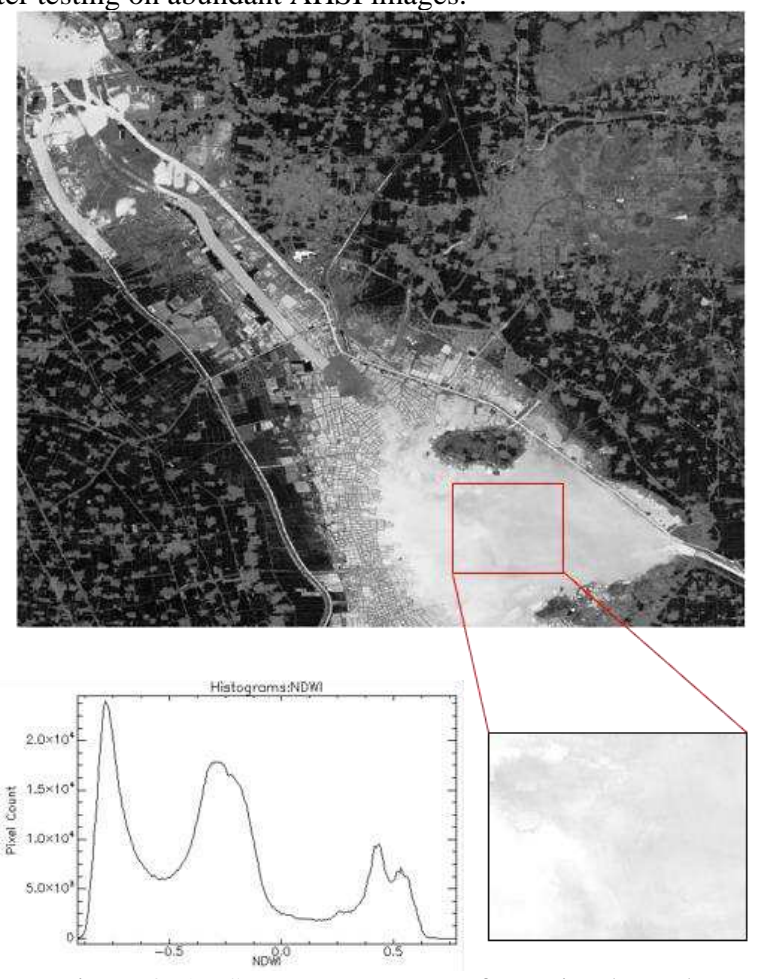

Figure 3. AHSI's NDWI Image of Nansi Lake and Corresponding Histogram.

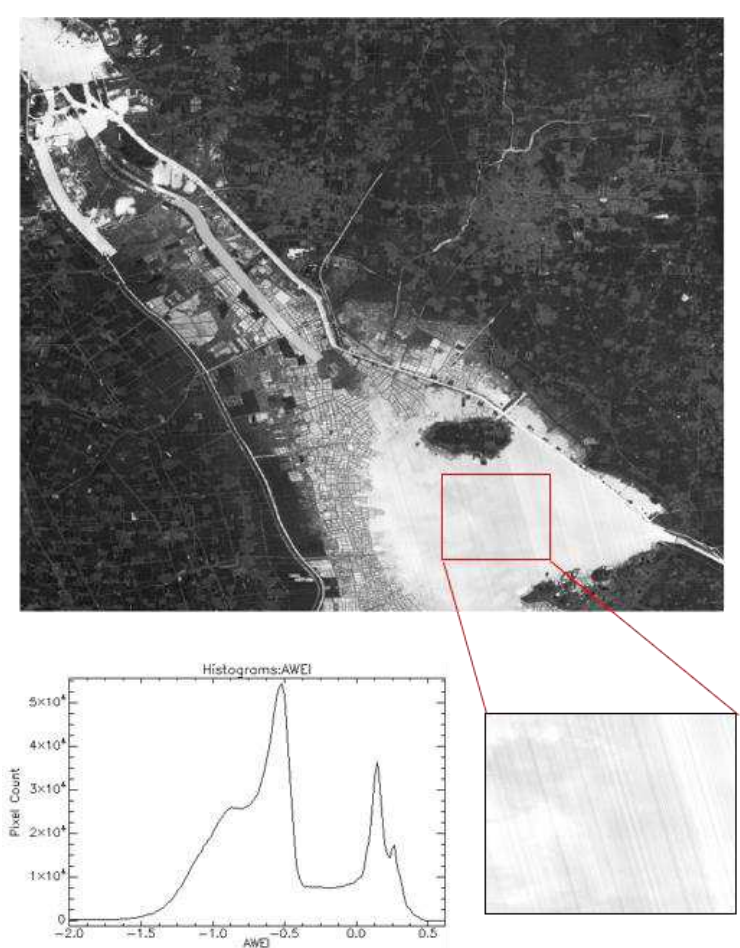

Figure 4. AHSI's MNDWI Image of Nansi Lake and Corresponding Histogram.

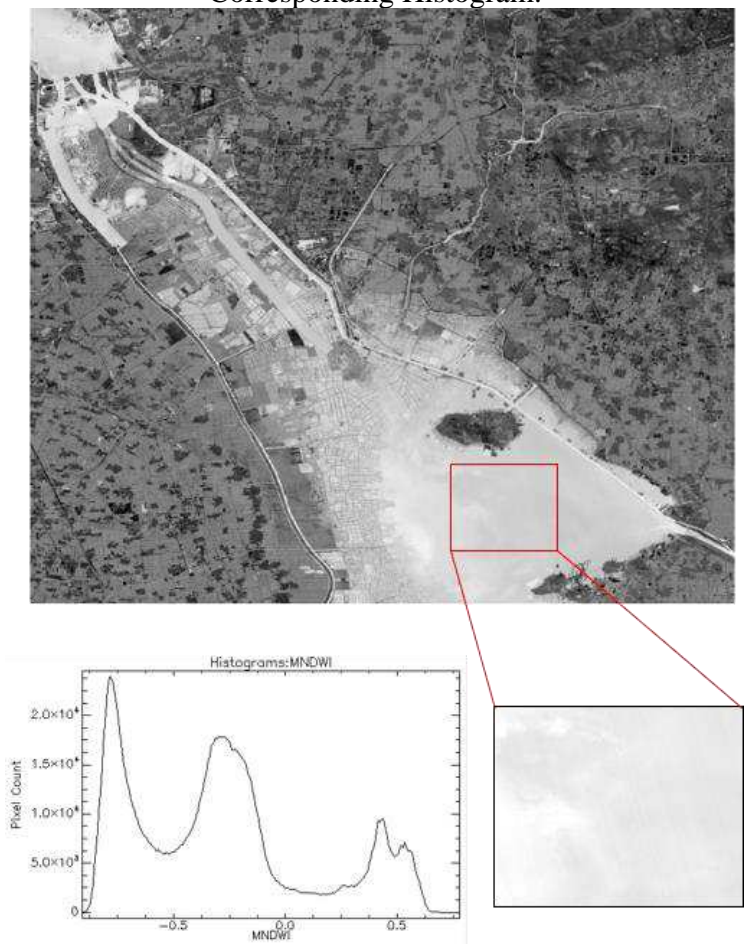

Figure 5. AHSI's AWEI Image of Nansi Lake and Corresponding Histogram.

From Figure 6-8, some insights for water extraction can be obtained for the Guanting Reservoir scene. First, MNDWI and NDWI have better ability to distinguish water and other surface materials, as their histograms have better valley shape for the threshold determination. Second, MNDWI still shows obvious strip noise in water pixels. Third, NDWI and MNDWI are better at suppressing surrounding cloud pixels than AWEI in the AHSI images. 

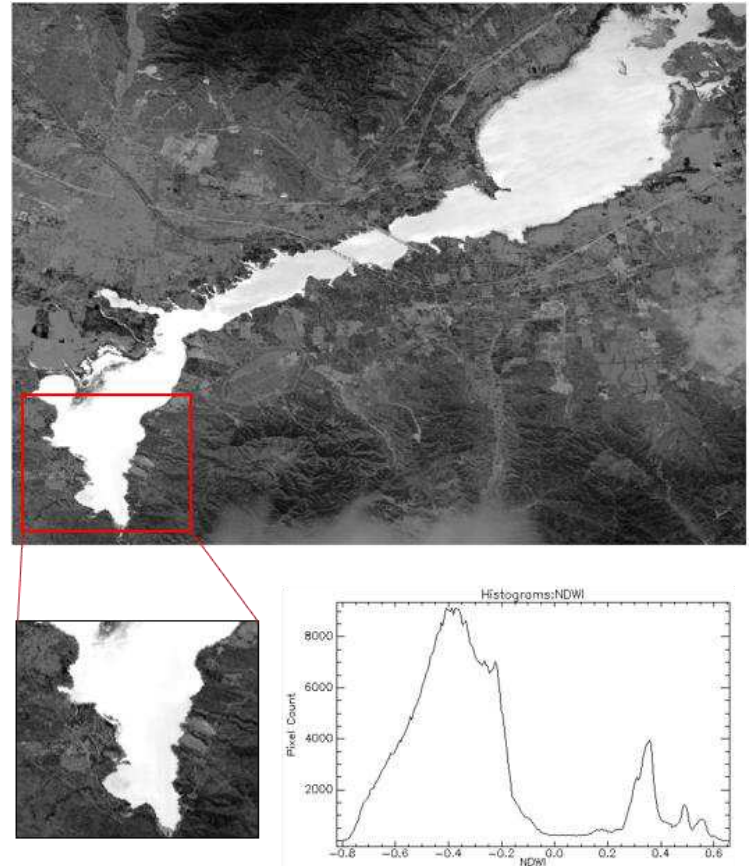

Figure 6. AHSI's NDWI Image of Guanting Reservoir and Corresponding Histogram.
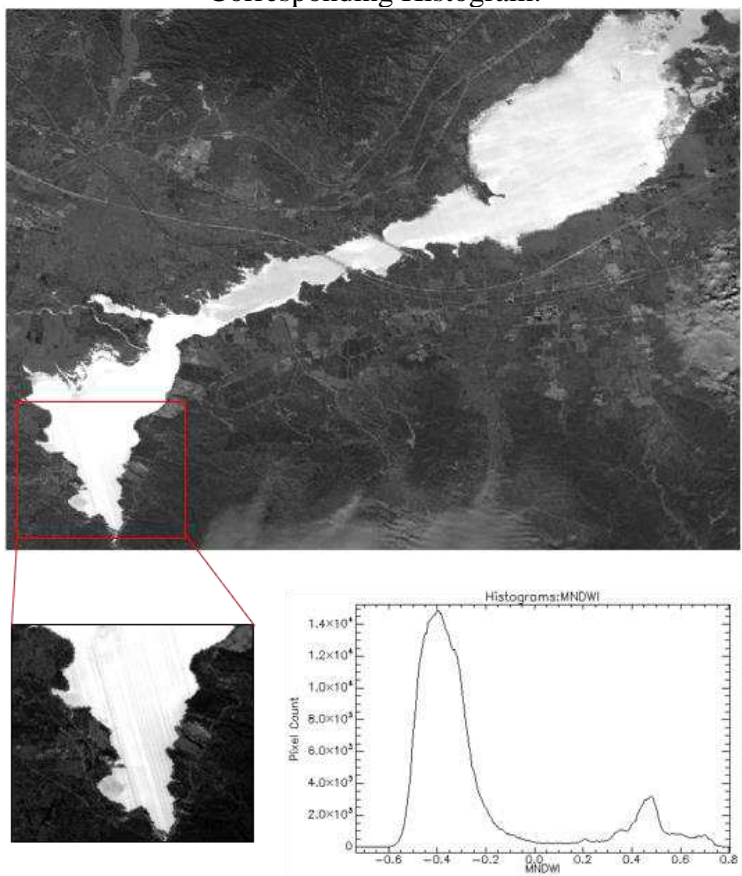

Figure 7. AHSI's MNDWI Image of Guanting Reservoir and Corresponding Histogram.

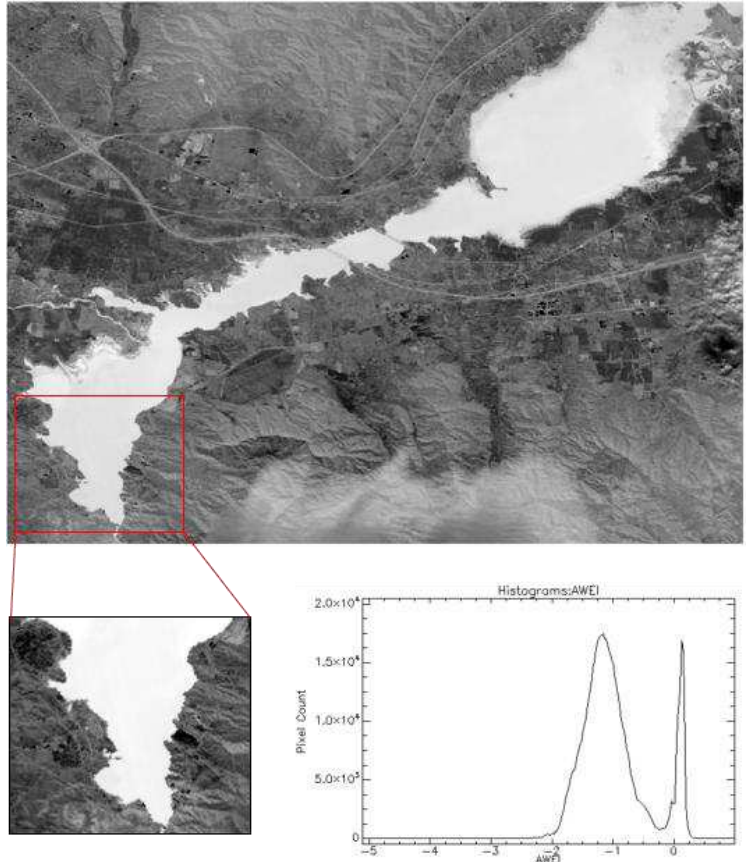

Figure 8. AHSI's AWEI Image of Guanting Reservoir and Corresponding Histogram.

According to above analysis made on the water index images, NDWI, MNDWI and AWEI ${ }_{n s h}$ all have their own weaknesses to be applied on the AHSI data. Multiple peaks may appear in the histogram of NDWI and AWEI images, whereas MNDWI can best differentiate water and non-water surfaces. On the other hand, noise in AHSI data has obvious effect on the MNDWI image, but not on the other two indices. Considering all these disadvantages and the different levels of difficulties to solve them, NDWI and MNDWI are thought to be better candidates than AWEI for the water extraction of the AHSI data.

\subsection{Water Extraction Results}

Thresholds were selected as the minimum in the valley of the histograms, so that the water areas were extracted and displayed in Figure 9 and 10. Pixels recognized as water are coloured in orange, and three major differences of extraction are also circled out for comparison. Extraction results from NDWI and MNDWI are basically the same, whereas water area delineated from $\mathrm{AWEI}_{n s h}$ recognized more fish ponds (circle 1-3) scattered in Nansi Lake. All the three results gave correct identifications for water areas.

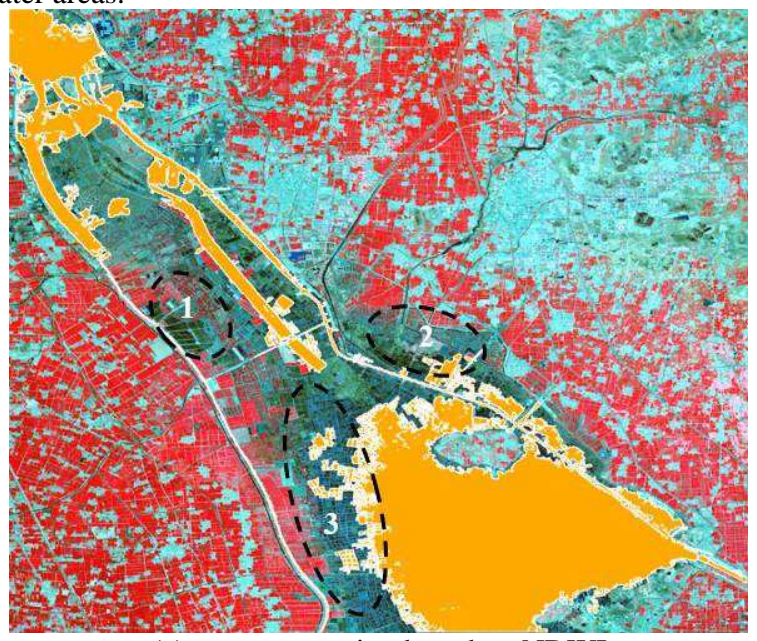

(a) water extraction based on NDWI 


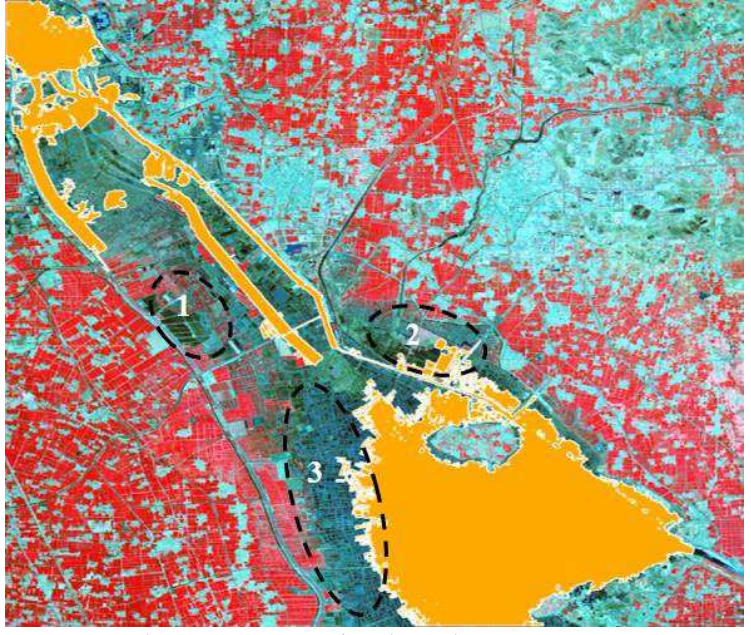

(b) water extraction based on MNDWI

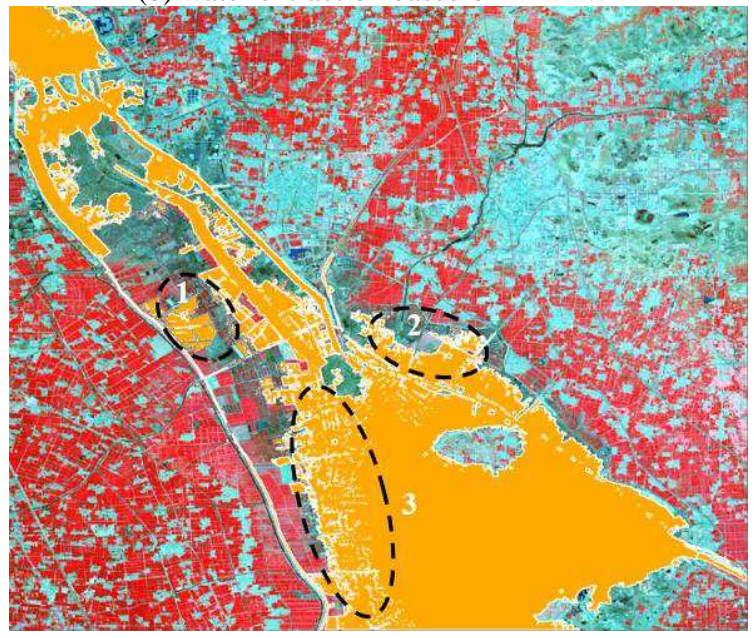

(c) water extraction based on AWEI

Figure 9. Water Extraction Results for the AHSI image of Nansi Lake

Water extraction results were more diverse in the case of Guanting Reservoir (see Figure 10). Comparing these water masks with its reflectance image, we have found that NDWI image gives the best extraction results, as it is the only one that distinguish pixels with water plant or flooded farmland (circle 1 and circle 2 on the image) from water area. Exclusion of these areas are important for conducting water quality parameter estimation. Furthermore, some shadow pixels (circle 3 on the image) exist between land and water in the Guanting Reservoir image, and water area extracted from NDWI provides the best performance of excluding these pixels.

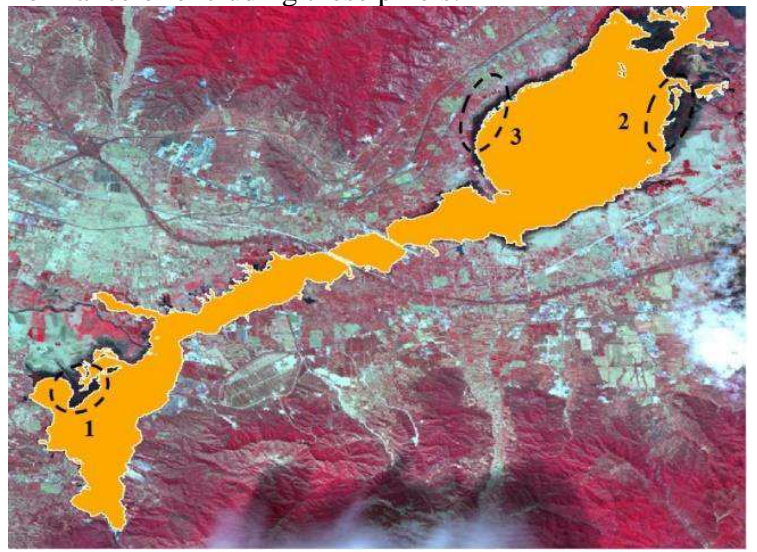

(a) water extraction based on NDWI

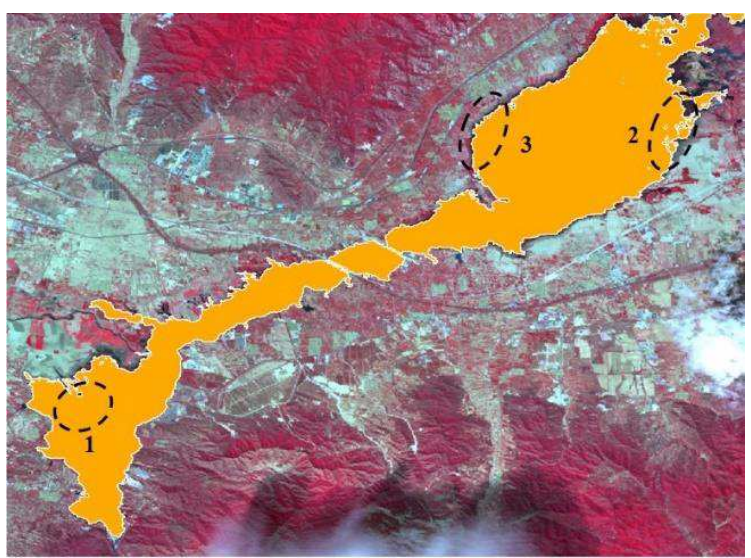

(b) water extraction based on MNDWI

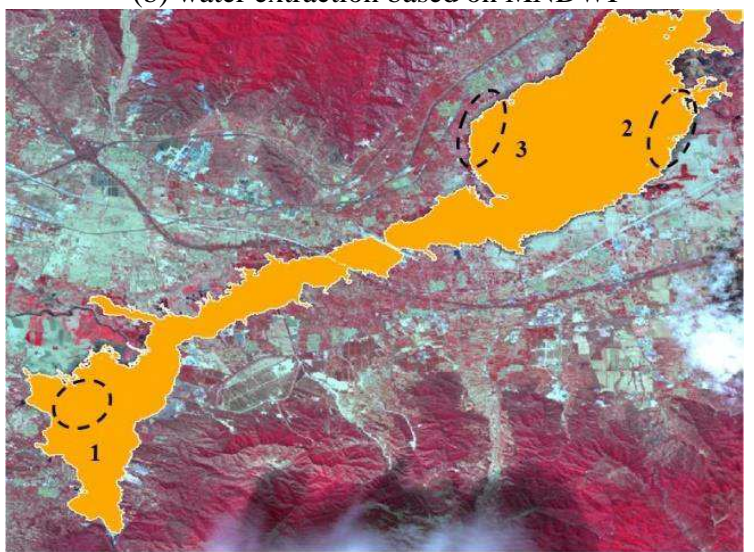

(c) water extraction based on AWEI

Figure 10. Water Extraction Results for the AHSI image of Guanting Reservoir

\section{CONCLUSION}

In this paper, water extraction for Gaofen-5's hyperspectral data was explored using the water index thresholding method. NDWI, MNDWI and AWEI $n$ sh were calculated for the AHSI surface reflectance data based on Landsat TM's band designation, and water areas were delineated using the histogram bimodal method. Experimental results show that NDWI outperforms other two spectral indices on the water extraction of the AHSI images, especially when the water body contains the water plant or the image has shadow pixels between land and water. Otherwise, all the three water indices can extract desirable water boundary for the AHSI data. In addition, MNDWI is more robust in terms of providing a bimodal shaped histogram than NDWI and AWEI. Although the MNDWI image shows most severely strip noise, this does not affect the water extraction results. Therefore, NDWI and MNDWI are suggested to be applied for the water extraction of AHSI data, and NDWI should be chosen for the water bodies having water plants.

\section{ACKNOWLEDGEMENTS}

This research was supported by the Project of natural resources satellite remote sensing technology system construction and application demonstration and National Natural Science Foundation of China under Grant No.41901304.

\section{REFERENCES}

Brando, V. E., Dekker, A. G., 2003. Satellite hyperspectral remote sensing for estimating estuarine and coastal water quality. 
IEEE transactions on geoscience and remote sensing, 41(6), $1378-1387$.

Chen, Y., Fan, R., Yang, X., Wang, J., Latif, A., 2018. Extraction of urban water bodies from high-resolution remote-sensing imagery using deep learning. Water, 10(5), 585.

Cooley, T., Anderson, G. P., Felde, G. W., Hoke, M. L., Ratkowski, A. J., Chetwynd, J. H., et al., 2002. FLAASH, a MODTRAN4-based atmospheric correction algorithm, its application and validation. IEEE International Geoscience and Remote Sensing Symposium, 3, 1414-1418.

Daya Sagar, B., Gandhi, G., Prakasa Rag, B., 1995. Applications of mathematical morphology in surface water body studies. International Journal of Remote Sensing, 16(8), 1495-1502.

Feng, L., Hou, X., Zheng, Y., 2019. Monitoring and understanding the water transparency changes of fifty large lakes on the Yangtze Plain based on long-term MODIS observations. Remote sensing of environment, 221, 675-686.

Feyisa, G. L., Meilby, H., Fensholt, R., Proud, S. R., 2014. Automated Water Extraction Index: A new technique for surface water mapping using Landsat imagery. Remote Sensing of Environment, 140, 23-35.

Guo, M., Li, J., Sheng, C., Xu, J., Wu, L., 2017. A review of wetland remote sensing. Sensors, 17(4), 777.

He, Y., Zhang, X., Hua, L., 2016. Object-based distinction between building shadow and water in high-resolution imagery using fuzzy-rule classification and artificial bee colony optimization. Journal of Sensors, 2016.

Isikdogan, F., Bovik, A. C., Passalacqua, P., 2017. Surface water mapping by deep learning. IEEE Journal of Selected Topics in Applied Earth Observations and Remote Sensing, 10(11), 49094918.

Jain, S. K., Singh, R., Jain, M., Lohani, A., 2005. Delineation of flood-prone areas using remote sensing techniques. Water Resources Management, 19(4), 333-347.

Kaplan, G., Avdan, U., 2017. Object-based water body extraction model using Sentinel-2 satellite imagery. European Journal of Remote Sensing, 50(1), 137-143.

Khandelwal, A., Karpatne, A., Marlier, M. E., Kim, J., Lettenmaier, D. P., Kumar, V., 2017. An approach for global monitoring of surface water extent variations in reservoirs using MODIS data. Remote sensing of Environment, 202, 113-128.

Koponen, S., Pulliainen, J., Kallio, K., Hallikainen, M., 2002. Lake water quality classification with airborne hyperspectral spectrometer and simulated MERIS data. Remote Sensing of Environment, 79(1), 51-59.

Li, J., Sheng, Y. W., Luo, J., 2011. Automatic extraction of Himalayan glacial lakes with remote sensing. Yaogan XuebaoJournal of Remote Sensing, 15(1), 29-43.

Liu, Y. N., Sun, D. X., Hu, X. N., Ye, X., Li, Y. D., Liu, S. F., Cao, K. Q., Chai, M. Y., Zhang, J., Zhang, Y. et al., 2019. The Advanced Hyperspectral Imager: Aboard China's GaoFen-5 Satellite. IEEE Geoscience and Remote Sensing Magazine, 7(4), 23-32.
McFeeters, S. K., 1996. The use of the Normalized Difference Water Index (NDWI) in the delineation of open water features. International journal of remote sensing, 17(7), 1425-1432.

Rai, P. K., Chandel, R. S., Mishra, V. N., Singh, P., 2018. Hydrological inferences through morphometric analysis of lower Kosi river basin of India for water resource management based on remote sensing data. Applied water science, 8(1), 15.

Rishikeshan, C., Ramesh, H., 2018. An automated mathematical morphology driven algorithm for water body extraction from remotely sensed images. ISPRS journal of photogrammetry and remote sensing, 146, 11-21.

Wang, R., Meng, Y., Zhang, W., Li, Z., Hu, F., Meng, L., 2019. Remote sensing semantic segregation for water information extraction: Optimization of samples via training error performance. IEEE Access, 7, 13383-13395.

Xu, H., 2006. Modification of normalised difference water index (NDWI) to enhance open water features in remotely sensed imagery. International journal of remote sensing, 27(14), 30253033.

Zhang, F., Li, J., Zhang, B., Shen, Q., Ye, H., Wang, S., Lu, Z., 2018. A simple automated dynamic threshold extraction method for the classification of large water bodies from landsat8 OLI water index images. International journal of remote sensing, 39(11), 3429-3451. 